\title{
Suicidal behavior and self-harm in girls with eating disorders
}

\author{
This article was published in the following Dove Press journal: \\ Neuropsychiatric Disease and Treatment \\ II April 2016 \\ Number of times this article has been viewed
}

\section{Jiri Koutek \\ Jana Kocourkova \\ Iva Dudova}

Department of Child Psychiatry, Charles University Second Faculty of Medicine, University Hospital Motol, Prague, Czech Republic
Correspondence: Jiri Koutek Department of Child Psychiatry, Charles University Second Faculty of Medicine, University Hospital Motol, V Uvalu 84, I 5006 Prague, Czech Republic

Tel +420 224433403

Fax +420224433420

Email jiri.koutek@|fmotol.cuni.cz

\begin{abstract}
Comorbid psychopathology, including self-harm and suicidal behavior, is often found in patients with eating disorders. To better understand the reasons for high comorbid psychopathology among eating disorders, self-harm, and suicidal behavior, we examined this comorbidity in female patients hospitalized with eating disorders. In a sample of 47 girls admitted for anorexia nervosa, atypical anorexia nervosa, and bulimia nervosa, $72 \%$ had depressive symptoms, $11 \%$ had obsessive-compulsive symptoms, $9 \%$ had anxiety disorder, $23 \%$ had substance abuse, and $57 \%$ had disharmonious personality development. Suicidal behavior was present in $60 \%$ of patients and self-harm in $49 \%$. Association was found between self-harm and suicidality. In all, $68 \%$ of girls with eating disorders had a positive score in the Children's Depression Inventory questionnaire and $62 \%$ of them in the Child Adolescent Suicidal Potential Index questionnaire. Clinical examination of girls with eating disorders should focus on identifying the risk of suicidal behavior and self-harm.
\end{abstract}

Keywords: eating disorders, child, adolescent, self-harm, suicidal behavior

\section{Introduction}

Suicidal behavior and self-harm occur relatively often in child and adolescent patients with eating disorders. The results of numerous studies vary depending on the groups of patients with eating disorders, in terms of specific disorders (anorexia nervosa and bulimia nervosa), duration of the disorder, or associated comorbidities with depression, personality disorders, or substance abuse. The results of numerous studies may vary in age composition or whether the patients are assessed during hospitalization or outpatient treatment. ${ }^{1-8}$

Suicide is one of the leading causes of death in anorexia nervosa and bulimia nervosa cases. $^{7}$ A suicide is defined as a self-inflicted death with evidence of intent to die. Not only suicide, but also unfinished suicidal behavior, has a great impact on individuals and on the functioning of the entire family system. The situation requires specific expert intervention. Recent studies show a higher prevalence of suicide in cases of anorexia nervosa; the prevalence of suicide attempts in anorexia nervosa is found to be in the range of 3\%-20\%. ${ }^{5}$ For example, Bulik et al $^{1}$ examined the prevalence of suicide attempts in anorexia nervosa and found that $\sim 16.9 \%$ of people with anorexia nervosa attempt suicide at some point during their lives. They found a relatively lower prevalence in patients with the restrictive type of anorexia nervosa (7.4\%) as compared to patients with purgative symptoms (26.1\%). The examination of suicidal behavior and self-harm in adolescent patients with eating disorders is clinically relevant because they are risk factors for suicidal behavior in adulthood..$^{9}$ Mayes et $\mathrm{al}^{6}$ reported a higher correlation between suicidal ideation and suicidal attempt in bulimia compared to anorexia nervosa. 
Self-harm is associated with conscious, intentional, often repeated self-harm without conscious suicidal motivation and severe lethal impact. ${ }^{10}$ It is often referred to as "deliberate self-harm syndrome", eg, cutting with a razor blade, scraping with a sharp object, and burning with cigarettes, but there are also less distinct forms that are being associated with the eating disorder pathology, eg, cold showers, extreme physical activity, tightening waist bands, drawing blood, and swallowing objects. The syndrome of deliberate self-harm is often present in cases of eating disorders, be it in the familiar form of self-cutting or in the form of medication overdose, which is, in the first diagnostic line, often classified as a suicide attempt. However, there may not be the intention, although ambivalent, to die, but this may rather be an attempt to convert psychological discomfort into somatic pain. ${ }^{11}$ Self-harm occurs relatively frequently (30\%-40\%) in patients with clinically diagnosed eating disorders..$^{3,12}$ The somatic condition of the patients is an important factor for self-harm and suicidal behavior in eating disorders. ${ }^{13}$ Sex differences and eating disorder risk among psychiatric conditions, compulsive behaviors, and substance use were studied by Davison et al. ${ }^{14}$ The authors emphasize the need of further investigation of suicidal ideation in relationship to eating disorder risk.

The aims of the study are to identify associations between eating disorders and suicidal and self-harm behavior in children and adolescents, to assess their family background and any family psychopathology, to find comorbid psychopathology and to compare the characteristics of suicidal behavior and self-harm in these patients, and to identify differences and potentially different risk aspects.

\section{Methods}

The target group of the research was all female patients admitted for eating disorders at the Department of Child Psychiatry of the University Hospital in Motol in 2013. All parents of patients included in this study provided written consent. The study was approved by the Ethics Committee of the University Hospital in Motol, Prague. In total, there were 47 girls aged between 10.25 to 18 years, with the average age of 15.5 years. Adolescent girls were more prevalent (Figure 1). The group was examined using the semistructured psychiatric and psychological interview, focusing on symptoms of eating disorders and their types, comorbid psychopathology, presence of suicidal behavior and self-harm, and also the family background and current level of stress. Interviews were conducted with the parents to establish their family history. Part of the examination was the Child Adolescent Suicidal Potential Index (CASPI) suicidal potential questionnaire and the Children's Depression Inventory (CDI) self-assessment questionnaire. The CASPI questionnaire contains 30 items that focus on depressive symptoms, suicidal motivation, and family problems. ${ }^{15}$ According to the authors, the CASPI total score for children and adolescents classified different levels of suicidal status with sensitivities ranging from $58 \%$ to $76 \%$ and specificities ranging from $58 \%$ to $72 \%$. CASPI total score of 11 distinguished suicidal ideation or acts from nonsuicidal behavior, with sensitivity

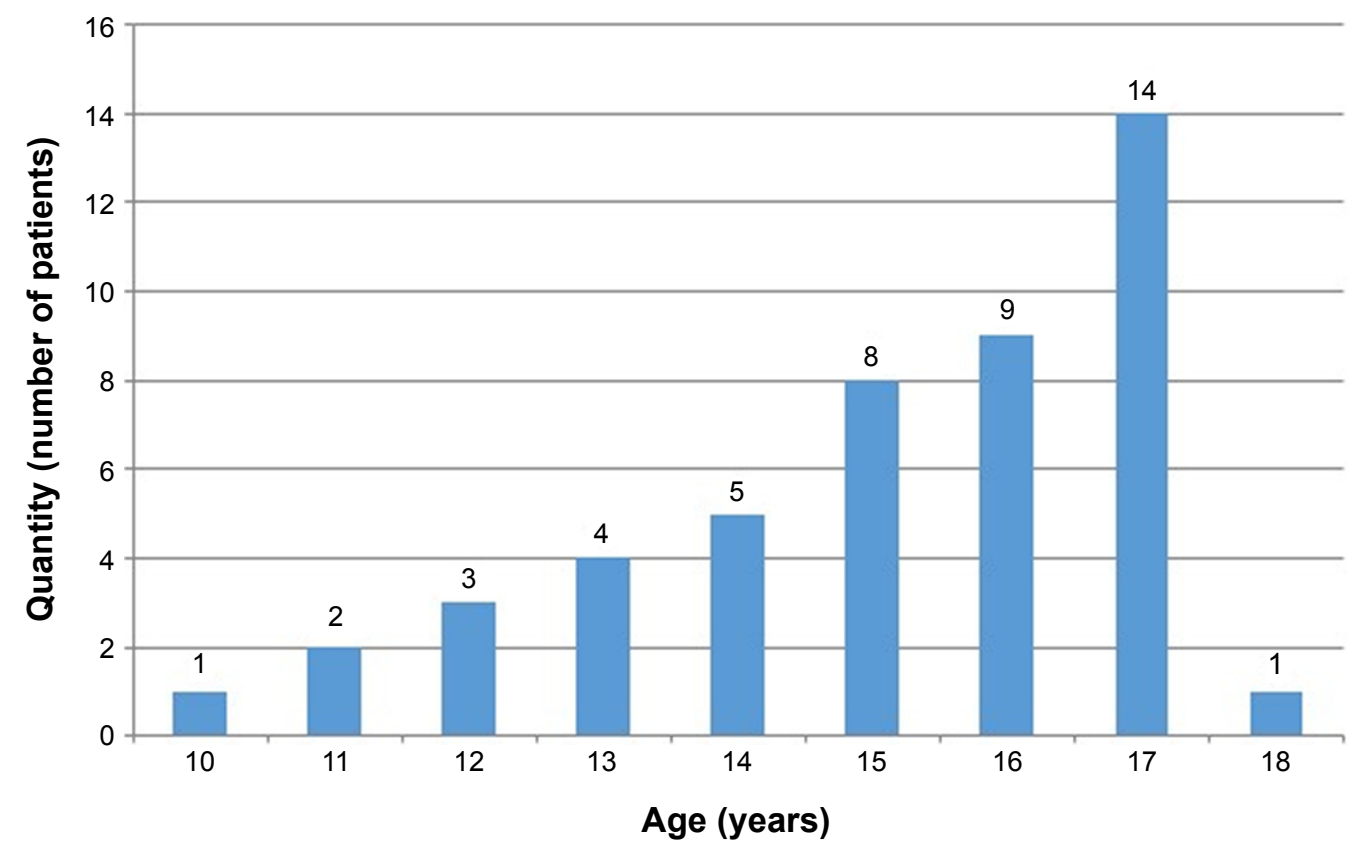

Figure I Age range of the sample. 
of $70 \%$ and specificity of $65 \% .{ }^{15}$ The CDI questionnaire is a 27-item self-assessment method for evaluating depression in children and adolescents. ${ }^{16}$ The author recommended that the cutoff score in clinical settings needs to be sensitive and is set at 13 . Kovacs reports alpha reliability coefficients ranging from 0.71 to $0.86 .^{16}$

The authors included suicidal ideation, suicidal tendencies, and suicidal attempts in the observed characteristics of suicidal behavior. Suicidal ideation was described as a repeated expression of the intention to commit suicide. Cases where the patient was preparing suicidal behavior (eg, collected medicaments with the aim of intoxication) were classified as suicidal tendencies. Suicidal attempts are defined as active self-harming act with the intention to die.

The statistical analysis was performed using Statistical Package for the Social Sciences Version 16.0 software (SPSS Inc., Chicago, IL, USA). Descriptive statistics were used to describe the group. The chi-squared test was used to determine the relationship between self-harm and suicidal behavior, between the CASPI positivity and suicidal behavior, between the CDI positivity and suicidal behavior, and between the CDI positivity and CASPI positivity.

\section{Results}

\section{Type of disorder and comorbid symptoms}

Typical anorexia nervosa was more prevalent in the group of 47 children and adolescents who were admitted for eating disorders - 36 patients (77\%), eight (17\%) were patients with atypical anorexia nervosa, and three $(6 \%)$ with bulimia nervosa. The average duration of eating disorder before admission was 15.5 months $( \pm 14)$. As for the presence of comorbid psychopathology, depression was present in 34 patients (72\%), obsessive-compulsive symptoms in five (11\%), anxiety disorders in four (9\%), and substance abuse in eleven (23\%) of the group. Disharmonious personality development was observed in $27(57 \%)$ (Table 1). Use of medication was in the treatment history of 16 patients (34\%), in 13 cases, they used selective serotonin reuptake inhibitor (SSRI) antidepressants. During hospitalization, psychiatric medication was induced in 32 patients (68\%), of whom 23 used SSRI antidepressants.

\section{Description of family and assessment of current stress level}

The family background of the patients tended to show adversities and their associated issues. In our group, 21 patients $(45 \%)$ had divorced parents. In terms of the family typology, 22 patients $(47 \%)$ lived in complete families with both biological parents, 17 (36\%) with one biological parent (mostly
Table I Type of disorder and comorbidity

\begin{tabular}{ll}
\hline Disorder & Frequency (\%) \\
\hline Eating disorders & $47(100)$ \\
Anorexia nervosa & $36(77)$ \\
Atypical anorexia nervosa & $8(17)$ \\
Bulimia nervosa & $3(6)$ \\
Comorbid disorders/symptoms & \\
Depression & $34(72)$ \\
Obsessive-compulsive symptoms & $5(1 \mathrm{I})$ \\
Anxiety disorder & $4(9)$ \\
Disharmonious personality development & $27(57)$ \\
Substance abuse & $\mathrm{II}(23)$ \\
\hline
\end{tabular}

the mother), and six (13\%) with one biological parent and her or his partner. In terms of family functionality, fully harmonious families were observed in 14 patients (30\%), functioning families with conflicts in 17 patients (36\%), and dysfunctional families in 15 patients (32\%) (Table 2). Subjectively experienced stress was related to mental disorder in 38 patients $(81 \%)$, family problems in 27 patients $(57 \%)$, and problems in relationships with peers in six patients $(13 \%)$. The stress factors were often combined (Figure 2).

\section{Presence of suicidal behavior and self-harm}

Suicidal behavior occurred in a total of $60 \%$ of the cases. In the context of this behavior, significant suicidal ideation occurred in 22 patients (47\%), suicidal tendencies were detected in two patients $(4 \%)$ with a preparation of suicidal behavior, and suicidal attempts occurred in four patients $(9 \%)$ (Figure 3). Self-harm occurred in $49 \%$ of the sample with a prevalence of self-cutting.

\section{Relationship between self-harm and suicidal behavior}

In the self-harm group $(\mathrm{N}=23)$, there were 17 patients with suicidal behavior (73.9\%). In the group without self-harm $(\mathrm{N}=24)$, there were eleven patients with suicidal

Table 2 Family characteristics in the sample

\begin{tabular}{ll}
\hline Family characteristics & Frequency (\%) \\
\hline Divorce of parents & $21(45)$ \\
Family typology & \\
Complete (both biological parents) & $22(47)$ \\
One biological parent & $17(36)$ \\
One biological parent and partner & $6(13)$ \\
Other & $2(4)$ \\
Family functionality & \\
Fully harmonious & $14(30)$ \\
Functioning with conflicts & $17(36)$ \\
Dysfunctional & $15(32)$ \\
Other & $1(2)$ \\
\hline
\end{tabular}




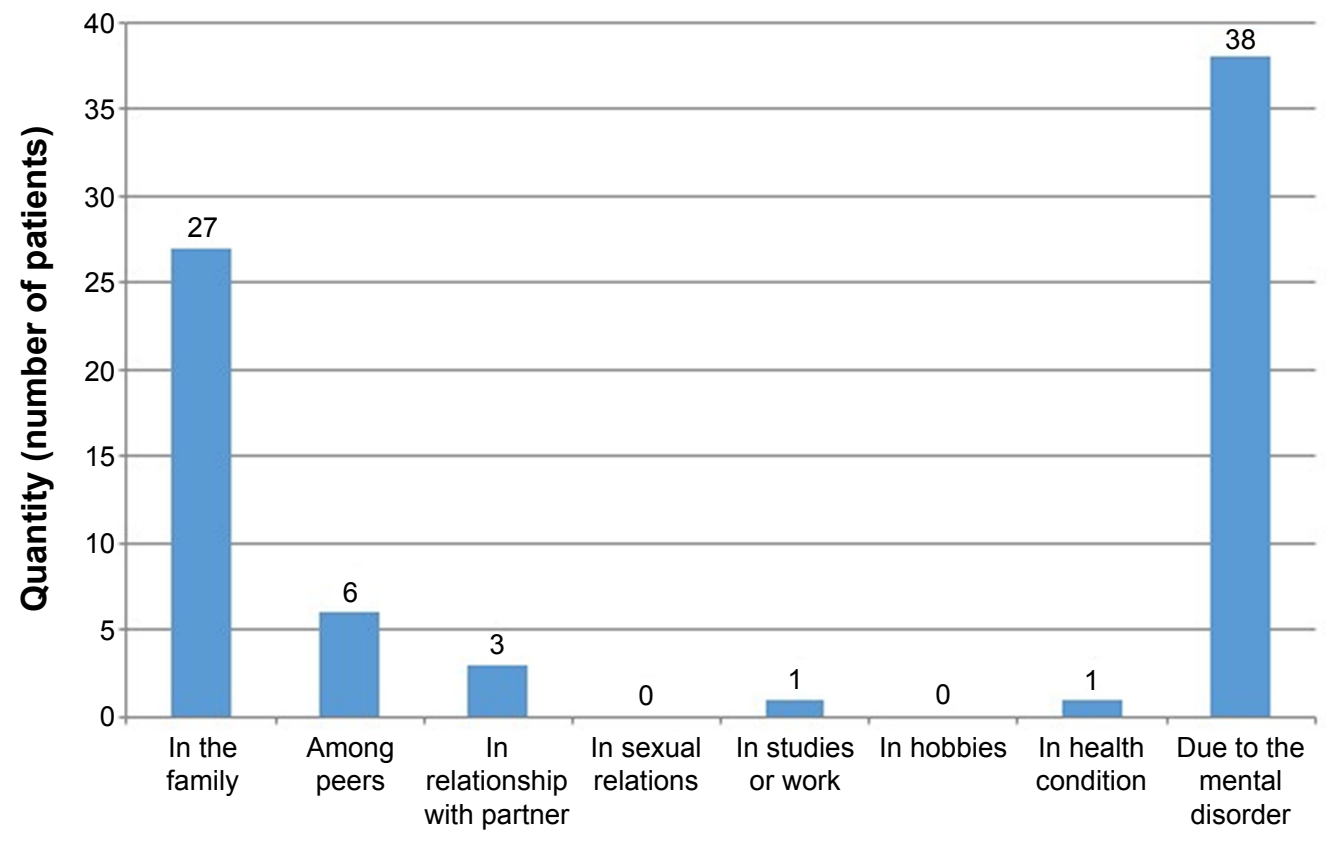

Current stress factors

Figure 2 Current stress factors in the sample.

behavior (45.8\%). The difference is statistically significant, chi-square test (asymptotic significance, two sided), $P=0.050$ (Table 3).

\section{Evaluation of CASPI suicidal potential questionnaire and CDI depressiveness self-assessment scale}

In the CASPI questionnaire, the cutoff score of suicidal risk is 11 points. An increased score of suicidal risk was established in 29 patients (62\%) in our group. In the CDI self-assessment scale, the cutoff score is 13 points. A clinically important

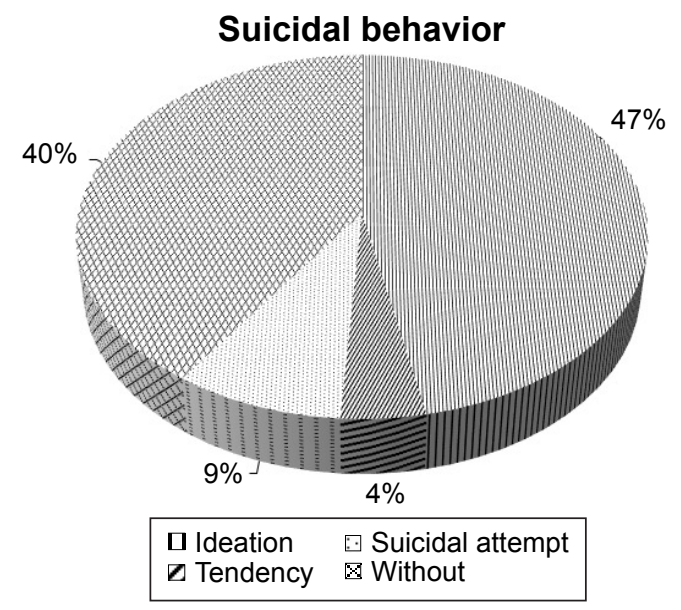

Figure 3 Presence of suicidal behavior. depressiveness score in the self-assessment CDI scale was found in 32 patients $(68 \%)$ in the cohort.

\section{Relationship between CASPI positivity and suicidal behavior}

In the CASPI-negative group $(\mathrm{N}=18)$, there were four patients with suicidal behavior (22.2\%). In the CASPIpositive group $(\mathrm{N}=29)$, there were 24 patients with suicidal behavior $(82.8 \%)$. The difference is highly significant, chi-square test (asymptotic significance, two sided), $P<0.0001$ (Table 4).

\section{Relationship between CDI positivity and suicidal behavior}

In the CDI-negative group $(\mathrm{N}=15)$, there were five patients with suicidal behavior (33.3\%). In the CDI-positive group $(\mathrm{N}=32)$, there were 23 patients with suicidal behavior

Table 3 Relationship between self-harm and suicidal behavior

\begin{tabular}{|c|c|c|c|c|}
\hline \multirow[t]{2}{*}{ Characteristics } & \multicolumn{3}{|c|}{$\begin{array}{l}\text { Suicidal behavior (ideation or } \\
\text { tendency or attempt) }\end{array}$} & \multirow[t]{2}{*}{ Total } \\
\hline & & No & Yes & \\
\hline \multicolumn{5}{|c|}{ History of self-harm } \\
\hline \multirow[t]{2}{*}{ No } & Number & 13 & 11 & 24 \\
\hline & $\%$ & 54.2 & 45.8 & 100 \\
\hline \multirow[t]{2}{*}{ Yes } & Number & 6 & 17 & 23 \\
\hline & $\%$ & 26.1 & 73.9 & 100 \\
\hline
\end{tabular}

Note: Chi-square test (asymptotic significance, two sided), $P=0.050$ as indicated by the bold values. 
Table 4 Relationship between CASPI positivity and suicidal behavior

\begin{tabular}{lllll}
\hline Characteristics & \multicolumn{2}{l}{$\begin{array}{l}\text { Suicidal behavior (ideation } \\
\text { or tendency or attempt) }\end{array}$} & Total \\
\cline { 2 - 4 } & Number & 14 & 4 & 18 \\
\hline CASPI negative & $\%$ & 77.8 & $\mathbf{2 2 . 2}$ & 100 \\
& Number & 5 & 24 & 29 \\
CASPI positive $(>I I)$ & $\%$ & 17.2 & $\mathbf{8 2 . 8}$ & 100 \\
\hline
\end{tabular}

Note: Chi-square test (asymptotic significance, two sided), $P=0.000 \mathrm{I}$ as indicated by the bold values.

Abbreviation: CASPI, Child Adolescent Suicidal Potential Index.

$(71.9 \%)$. The difference is highly significant, chi-square test (asymptotic significance, two sided), $P=0.012$ (Table 5).

\section{Relationship between CDI positivity and CASPI positivity}

In the CDI-negative group ( $\mathrm{N}=15)$, there were four patients with positive CASPI results (26.7\%). In the CDI-positive group ( $\mathrm{N}=32)$, there were 25 patients with positive CASPI results (78.1\%). The difference is highly significant, chi-square test (asymptotic significance, two sided), $P=0.001$ (Table 6).

\section{Discussion}

In our study group, the majority of adolescent girls were diagnosed with anorexia nervosa, with a smaller number of atypical anorexia nervosa cases, and an insignificant number of bulimia nervosa cases. This distribution of eating disorders corresponds to the age structure of the group. ${ }^{17}$ The presence of comorbid psychopathology in eating disorders is frequent. It is typically connected with depression, obsessive compulsive symptoms, substance abuse, and anxiety symptoms. This is also consistent with the literature. ${ }^{18,19}$ In our study, the most frequent comorbidities were depressive syndromes, which were found in 34 patients $(72 \%)$.

Table 5 Relationship between CDI positivity and suicidal behavior

\begin{tabular}{|c|c|c|c|c|}
\hline \multirow[t]{2}{*}{ Characteristics } & \multicolumn{3}{|c|}{$\begin{array}{l}\text { Suicidal behavior (ideation } \\
\text { or tendency or attempt) }\end{array}$} & \multirow[t]{2}{*}{ Total } \\
\hline & & No & Yes & \\
\hline \multirow[t]{2}{*}{ CDI negative } & Number & 10 & 5 & 15 \\
\hline & $\%$ & 66.7 & 33.3 & 100 \\
\hline \multirow[t]{2}{*}{ CDI positive $(>13)$} & Number & 9 & 23 & 32 \\
\hline & $\%$ & 28.1 & 71.9 & 100 \\
\hline
\end{tabular}

Note: Chi-square test (asymptotic significance, two sided), $P=0.012$ as indicated by the bold values.

Abbreviation: CDI, Children's Depression Inventory.
Table 6 Relationship between CDI positivity and CASPI positivity

\begin{tabular}{|c|c|c|c|c|}
\hline \multirow[t]{2}{*}{ Questionnaire } & \multicolumn{3}{|c|}{ CASPI positive } & \multirow[t]{2}{*}{ Total } \\
\hline & & No & $\overline{\text { Yes }}$ & \\
\hline \multirow{2}{*}{$\overline{C D I}$ negative } & Number & II & 4 & 15 \\
\hline & $\%$ & 73.3 & 26.7 & 100 \\
\hline \multirow[t]{2}{*}{ CDI positive $(>\mid 3)$} & Number & 7 & 25 & 32 \\
\hline & $\%$ & 21.9 & 78.1 & 100 \\
\hline
\end{tabular}

Note: Chi-square test (asymptotic significance, two sided), $P=0.00 \mathrm{I}$ as indicated by the bold values.

Abbreviations: CDI, Children's Depression Inventory; CASPI, Child Adolescent Suicidal Potential Index.

Almost half of the patients had previous disharmonious personality development.

Religiosity represents a protective factor for suicidal behavior. ${ }^{20}$ Chylová et $\mathrm{al}^{21}$ reported a lower prevalence of suicidal thoughts in deeply religious females. In our study, we did not establish religious beliefs, only information about belief in the afterlife. We found that 25 patients (53\%) believed that some form of life would continue after death.

The occurrence of suicidal behavior was observed in more than a half of the patients, particularly in the context of serious suicidal thoughts. There were also preparatory suicidal activities and realized suicide attempts. The high prevalence of suicidal behavior in patients with eating disorders is consistent with the literature. ${ }^{8}$ The suicidal behavior was associated with depressive symptoms; however, it was often significantly linked to eating disorder symptoms. As for the motivation, the girls reported forced eating, treatment, and fear of "becoming fat". They often said, "If I gain weight, then life will be worthless for me. I am nothing, it is better not to be at all". The literature suggests that suicidal behavior is closely linked to self-harm, which in itself does not aim to die but is a major risk factor for suicidal behavior. ${ }^{22}$ Our study confirmed this statement. Self-harm occurred in almost half of the patients in our group, and these patients showed a statistically significant increase in the risk of suicidal behavior.

The results of the CASPI and CDI questionnaire methods confirm the increased risk of suicidal and self-harm behavior as well as the presence of depressive symptoms. The CASPI and CDI positivity is associated with the clinical occurrence of self-harm and suicidal behavior. As for the assessment of the family background, problems in the functioning of families can be stated as follows: only a minority of patients live in a harmonious family environment and more than a half of them subjectively experience stress associated with the family. Problematic family relations are an important risk factor for suicidal behavior in childhood and adolescence. ${ }^{23,24}$ The biggest current stress, however, is evoked by the eating disorder 
itself, as it increases the risk of conflicts in the family. These conflicts are associated particularly with the eating behavior of the patient, her weight, and eating habits.

The studied group included only girls, as there was only one boy admitted to our department due to an eating disorder. He was not included in the group. The situation is consistent with the data from literature referring to the predominance of girls over boys in the incidence of eating disorders. ${ }^{17}$ Our clinical experience shows, however, that the ratio is $<10: 1$ in favor of girls with a higher prevalence in boys at a younger age.

The study results are limited by the small number of the investigated sample and the use of the self-report scales. The lower number of patients with mental bulimia is in line with the incidence of eating disorders in childhood and adolescence. The study focused only on girls admitted with eating disorders.

\section{Conclusion}

The results of our study show, in accordance with literature, that adolescent girls with eating disorders are at an increased risk of suicidal behavior and self-harm. The results of our study suggest that self-harm is connected with suicidal behavior. In our study, eating disorders were associated with suicidal behavior and, at the same time, with conflicts in the family. These two factors potentiated each other. For good clinical practice, the authors recommend that during the examination of child and adolescent patients with eating disorders, pediatricians, pediatric psychiatrists, and psychologists should focus on the potential risk of self-harm and suicide. In addition to psychiatric and psychological examination, the CASPI and the CDI questionnaires can prove to be useful methods for the assessment of depressiveness, suicidality, and self-harm in children and adolescents with eating disorders.

\section{Acknowledgments}

This work was supported from the project of the Ministry of Health of the Czech Republic for the conceptual development of the research organization 00064203 (University Hospital in Motol) and programme for the development of scientific disciplines at Charles University P07 Psychosocial aspects of human life quality.

\section{Disclosure}

The authors report no conflicts of interest in this work.

\section{References}

1. Bulik CM, Thornton L, Pinheiro AP, et al. Suicide attempts in anorexia nervosa. Psychosom Med. 2008;70(3):378-383.

2. Favaro A, Santonastaso P. Suicidality in eating disorders: clinical and psychological correlates. Acta Psychiatr Scandinavica. 1997;95(6): 508-514.

3. Favaro A, Santonastaso P. Self-injurious behavior in anorexia nervosa. J Nerv Menl Dis. 2000;188(8):537-542.

4. Fennig S, Hadas A. Suicidal behaviour and depression in adolescents with eating disorders. Nord J Psychiatry. 2010;64(1):32-39.

5. Franko DL, Keel PK. Suicidality in eating disorders: occurrence, correlates, and clinical implications. Clin Psychol Rev. 2006;26(6):769-782.

6. Mayes SD, Fernandez-Mendoza J, Baweja R, et al. Correlates of suicide ideation and attempts in children and adolescents with eating disorders. Eat Disord. 2014;22(4):352-366.

7. Pompilli M, Girardi P, Tatarelli G, Ruberto A, Tatarelli R. Suicide and attempted suicide in eating disorders, obesity and weight-image concern. Eat Behav. 2006;7(4):384-394.

8. Suokas JT, Suvisaari JM, Grainger M, Raevuori A, Gissler M, Haukka J. Suicide attempts and mortality in eating disorders: a follow-up study of eating disorder patients. Gen Hosp Psychiatry. 2014;36(3):355-357.

9. Johnson JG, Cohen P, Kasen S, Brook JS. Eating disorders during adolescence and the risk for physical and mental disorders during early adulthood. Arch Gen Psychiatry. 2002;59:545-552.

10. Skegg K. Self-harm. Lancet. 2005;366:1471-1483.

11. Jacobson CM, Gould M. The epidemiology and phenomenology of non-suicidal self-injurious behavior among adolescents: a critical review of the literature. Arch Suicide Res. 2007;11(2):129-147.

12. Claes L, Vandereycken W, Vertommen H. Self-care versus self-harm: piercing, tattooing, and self-injuring in eating disorders. Eur Eat Disord Rev. 2005;13:11-18.

13. Krásničanová H, Veselá M, Vejvalka J, Koutek J. Selected auxiological aspects of anorexia nervosa-relations of body weight to body height and menstrual cycle. Neuroendocrinol Lett. 2007;28(4):527-534.

14. Davison KM, Marshall-Fabien GL, Gondara L. Sex differences and eating disorder risk among psychiatric conditions, compulsive behaviors and substance use in a screened Canadian national sample. Gen Hosp Psychiat. 2014;36(4):411-414.

15. Pfeffer CR, Jiang H, Kakuma T. Child-Adolescent Suicidal Potential Index (CASPI): a screen for risk for early onset suicidal behaviour. Psychol Assess. 2000;12:304-318.

16. Kovacs M. The Children's Depression Inventory. North Tonawanda, NY: Multi-Health Systems; 1992.

17. Papežová H. Spektrum poruch př́jmu potravy [Eating disorders spectrum]. Praha: Grada; 2010. Czech.

18. Krch F. Poruchy príjmu potravy [Eating disorders]. Praha: Grada; 2005. Czech.

19. Papežová H, Kocourková J, Koutek J. Poruchy př́ijmu potravy. In: Raboch J, et al, editors. Doporučené postupy psychiatrické péče IV [The clinical practice guidelines for psychiatric care]. Praha: Psychiatrická společnost ČLS JEP; 2014. Czech.

20. Nelson G, Hanna R, Houri A, Klimes-Dougan B. Protective functions of religious traditions for suicide risk. Suicidol Online. 2012;3:59-71.

21. Chylová M, Pálová E, Kovaničková M. Breznoščáková. Prieskum suicidálnoho správania v období dospievania [Survey of suicidal behavior in adolescence]. Cesk Psychol. 2011;55(4): 306-315. Czech.

22. Wilkinson PO. Nonsuicidal self-injury: a clear marker for suicide risk. J Am Acad Child Adolesc Psychiatry. 2011;50(8):741-743.

23. Brent DA. Preventing youth suicide: time to ask how. J Am Acad Child Adolesc Psychiatry. 2011;50(8):738-740.

24. Koutek J, Kocourková J, Hladíková M, Hrdlička M. Suicidal behaviour in children and adolescents: does a history of trauma predict less severe suicidal attempts? Neuroendocrinol Lett. 2009;30(1):99-106. 
Neuropsychiatric Disease and Treatment

Dovepress

\section{Publish your work in this journal}

Neuropsychiatric Disease and Treatment is an international, peerreviewed journal of clinical therapeutics and pharmacology focusing on concise rapid reporting of clinical or pre-clinical studies on a range of neuropsychiatric and neurological disorders. This journal is indexed on PubMed Central, the 'PsycINFO' database and CAS,

and is the official journal of The International Neuropsychiatric Association (INA). The manuscript management system is completely online and includes a very quick and fair peer-review system, which is all easy to use. Visit http://www.dovepress.com/testimonials.php to read real quotes from published authors.

Submit your manuscript here: http://www.dovepress.com/neuropsychiatric-disease-and-treatment-journal 